\title{
New insights into sublithospheric Type IIa and Type IIb diamonds
}

\author{
E.M. SMITH ${ }^{1 *}$ AND W. WANG ${ }^{1}$
}

${ }^{1}$ Gemological Institute of America, $50 \mathrm{~W} 47^{\text {th }}$ Street, New York, NY 10036, USA (*correspondence:

evan.smith@gia.edu)

In the past few years, two new diamond varieties have been characterized as sublithospheric, or super-deep, in origin. Ongoing studies of new inclusion-bearing specimens continue to improve our understanding of type IIa (more specifically, CLIPPIR) and type IIb diamonds.

CLIPPIR diamonds are a variety epitomized by large and high quality type IIa gem diamonds, such as the 3106 carat Cullinan diamond [1]. Among their inclusions are examples of majoritic garnet and inferred $\mathrm{CaSiO}_{3}$-perovskite, suggesting a formation depth in the range of 360 to $750 \mathrm{~km}$ $[1,2]$. Type IIb diamonds (boron-bearing) host inclusions of ferropericlase as well as retrogressed majoritic garnet, $\mathrm{CaSiO}_{3}$-perovskite, CF-type phase, stishovite, and bridgmanite [3]. The mineral assemblage suggests an origin deeper than $360 \mathrm{~km}$, likely in the transition zone to uppermost lower mantle.

The relationship between these two similar diamond varieties remains somewhat unclear. Studies to date have left open the possibility that CLIPPIR diamonds might be formed at distinctly shallower depths than type IIb's, without any overlap. An additional large (>100 carats) rough CLIPPIR diamond has now been examined that contains inclusions of retrogressed aluminous bridgmanite. This is the first evidence of CLIPPIR diamond growth in the lower mantle, meaning there must be some overlap between the depth of formation for CLIPPIR and type IIb diamonds. A related issue concerning depth of formation, for type IIb diamonds [4], has also been addressed by examination of a new specimen. A large $(>10 \mathrm{ct})$ type IIb diamond has been found to contain former bridgmanite, which helps to dissolve the apparent dichotomy between inclusions in larger $(>2 \mathrm{ct})$ and smaller $(<2 \mathrm{ct})$ type IIb diamonds $[4,5]$. These recently examined specimens are helping to build a clearer picture of the paragenesis and geochemical implciations of these exquisite gem diamonds.

[1] Smith et al. (2016) Science 354, 1403-1405. [2] Smith et al. (2017) Gems \& Gemology 53, 388-403. [3] Smith et al. (2018) Nature 560, 84-87. [4] Moore \& Helmstaedt (2019) Nature 570, E26-E27. [5] Smith et al. (2019) Nature 570, E28-E29. 